\title{
Literatura infantil e multimodalidade: o papel dos paratextos no livro ilustrado
}

\author{
Tatyane Andrade Almeida \\ Universidade Federal de Minas Gerais \\ Celia Abicalil Belmiro \\ Universidade Federal de Minas Gerais
}

\begin{abstract}
Resumo
Este trabalho ${ }^{1}$ tem por objetivo analisar, a partir da perspectiva da multimodalidade, os paratextos dos livros de literatura infantil premiados pela FNLIJ na categoria Criança. De acordo com Genette (2009), o paratexto de uma obra é composto pelas produções, verbais ou não, que acompanham o texto verbal, como por exemplo, o título, o nome do autor, o prefácio etc., e que contribuem em sua apresentação e consumo. Aliada à concepção de multimodalidade, foram analisadas as informações paratextuais apresentadas nas capas, contracapas, orelhas e folhas de rosto de 57 livros infantis premiados, tendo em vista suas dimensões gráficas e discursivas. Buscou-se, dessa forma, evidenciar as modificações sofridas pelo livro infantil ao longo do tempo, como, por exemplo, a importância dada às ilustrações na construção da narrativa, e o que estas transformações nos dizem sobre as concepções de livro, literatura e criança.
\end{abstract}

Palavras-chave: literatura infantil, livro ilustrado, paratexto, multimodalidade.

\begin{abstract}
The aim of this paper is to employ the perspective of multimodality to analyze the paratexts of children's literature books that were given awards by FNLIJ in the category CHILD. According to Genette (2009), the paratext of a book is composed of productions, verbal or non verbal, that come together with the verbal text, such as title, author's name, preface and so on, that contribute to its presentation and consumption. Combined with the concept of multimodality, the paratextual information presented on the front covers, back covers, the ears of the books and the cover sheet of 57 awardwinning children's books were analyzed, with respect to their graphic and discourse dimensions. The analysis is an attempt to clarify the changes undergone by children's books over time, as, for example, the importance of the illustrations for building the narrative and what these changes tell us about the conceptions of book, literature and child.
\end{abstract}

Keywords: children's literature, picture book, paratext, multimodality

\footnotetext{
${ }^{1}$ Este artigo baseia-se em pesquisa de mestrado, com defesa em 08 de julho de 2016, pelo Programa de PósGraduação em Educação: Conhecimento e Inclusão Social da UFMG, com apoio da Capes.
} 


\section{INTRODUÇÃO}

A produção contemporânea de livros de literatura, tanto para crianças como também para jovens e adultos, tem revelado a frequência e a importância de elementos multimodais, caracterizando obras que propõem interfaces interessantes entre linguagens, sistemas semióticos e mídias e que nos surpreendem com hibridizações e formas que não se ajustam aos recortes teóricos que estamos habituados a considerar (BELMIRO, 2015).

Segundo Kress e Bezemer (2000), o conceito de multimodalidade refere-se a representações em vários modos, recursos semióticos configurados social $\mathrm{e}$ culturalmente para produzir significados. O que se considera como modo é aquilo que as comunidades determinam como tal a partir de suas necessidades sociais de representação. Dessa forma, imagens, palavras, composição da página, fala, imagem em movimento e gesto são alguns exemplos desses modos.

É nesse sentido que o livro infantil vem se constituindo como objeto multimodal, em que diferentes modos são escolhidos pela conveniência de seus potenciais comunicativos. Observa-se que, no processo de produção de uma obra, a escolha por um determinado modo se dá em virtude de seus potenciais semióticos, ou seja, suas possibilidades na criação de significados, tendo em vista os interesses e intenções dos criadores de textos - escritores, ilustradores, editores, designers.

Aproximações com a linguagem dos quadrinhos, do cinema, da fotografia, da pintura e do design redimensionam a prevalência dada à centralidade do texto verbal nos livros infantis para ceder lugar a outros modos de representação, especialmente os de cunho visual. A palavra recupera sua dimensão gráfica e imagética, a exemplo da poesia concretista, e articula-se às ilustrações ampliando as possibilidades de sentido. As escolhas editoriais - formato, diagramação, tipografia, qualidade do papel etc. -, ou seja, toda a concepção da materialidade do livro infantil é pensada como espaços de significação, complexificando as noções de autoria, endereçamento e as definições do próprio objeto.

O objetivo deste trabalho é analisar os elementos paratextuais de livros de literatura infantil premiados pela Fundação Nacional do Livro Infantil e Juvenil (FNLIJ) na categoria Criança. Busca-se, dessa forma, apreender, a partir da perspectiva da multimodalidade, algumas das modificações por que o livro de literatura infantil tem 
passado ao longo dos 40 anos da premiação e o que estas transformações nos dizem sobre as concepções de livro, literatura e criança.

\section{O PAPEL DOS PARATEXTOS NOS LIVROS INFANTIS ILUSTRADOS}

Os elementos paratextuais compõem uma estrutura que envolve o texto, assinalando um modo de organização que o coloca em relação a outros textos que o cercam e contribuem para que tome forma e produza sentidos. Os paratextos - título, subtítulo, prefácio, epígrafe, dedicatória, frontispício, guarda ${ }^{2}$, capa e quarta capa, entre outros - apresentam o texto, orientam um modo de leitura e atuam como uma porta de entrada propiciando sua recepção e consumo (GENETTE, 2009).

Segundo Genette (2009, p. 9), o texto "raramente se apresenta em estado nu, sem o reforço e o acompanhamento de certo número de produções, verbais ou não [...], que nunca sabemos se devemos ou não considerar parte dele, mas que em todo caso o cercam e o prolongam", garantindo sua presença no mundo. Batizado pelo autor de paratexto da obra, em texto de 1981, essa estrutura, à semelhança de um vestíbulo, "oferece a cada um a possibilidade de entrar, ou de retroceder" (Id., p. 9-10); zona de transição que atua sobre o público orientando tanto sua escolha quanto sua leitura, segundo as intenções de seus criadores.

Ainda que Genette não discuta a presença das imagens como elemento fundante de uma textualidade literária, podemos dizer que hoje a constituição do livro infantil supõe não só o texto verbal, mas também o texto visual, como um conjunto harmônico produtor de sentidos. No livro infantil ilustrado contemporâneo, frequentemente os elementos paratextuais constituem parte da narrativa, seja comunicando informações essenciais para sua compreensão, seja contradizendo a narrativa principal, produzindo, assim, novas combinações. Desse modo, os paratextos compõem a totalidade estética do livro ilustrado e interferem na relação do leitor com a obra. Segundo Nikolajeva e Scott (2011, p. 234), "a contribuição dos paratextos para o livro ilustrado é de fato muito importante, em especial porque costumam carregar uma porcentagem significativa das informações verbais e visuais do livro". As autoras destacam ainda que esse aspecto tem sido, em geral, negligenciado pelos críticos.

\footnotetext{
${ }^{2}$ Segundo o Dicionário Visual de Design Gráfico: "papel cartão espesso colado no início e final de um livro que une o bloco de texto a uma encadernação de capa dura. Às vezes, apresentam desenhos decorativos" (AMBROSE; HARRIS, 2009, p. 75).
} 
Contudo, observa-se que, cada vez mais, a atenção dos estudiosos ao livro ilustrado vem abarcando o livro em toda a sua integralidade. Necyk (2007) e Leite (2013) teorizam sobre a materialidade do livro em seus estudos, inclusive sobre os aspectos paratextuais e sua importância na composição do livro infantil. Linden (2011) nos oferece um amplo panorama sobre o livro ilustrado, considerado em suas múltiplas dimensões: histórica, material, plástica e discursiva. De maneira semelhante, a coletânea de textos organizada por Oliveira (2008) abrange uma série de aspectos relativos ao livro ilustrado, sendo um dos capítulos inteiramente destinado à discussão sobre projeto gráfico. Por outro lado, Powers (2012), embora não aborde o livro infantil como um todo, detém-se em um dos elementos paratextuais, a capa, dada a sua relevância para a compreensão do livro e de seu desenvolvimento.

As escolhas tipográficas, desde a capa até o miolo, potencializam a dimensão gráfica da escrita e têm uma forte presença como imagem. Christin (2006) apresenta uma importante discussão a respeito da origem da escrita e da imagem, indicando que a escrita carrega, na sua constituição, um traço de iconicidade, destacando o papel da imagem na invenção da escrita e na evolução de seus sistemas. Essa abordagem é cara aos que desejam pensar de forma mais inclusiva as possibilidades de interação de linguagens que são oferecidas no livro de literatura infantil nos dias atuais. O uso inovador das formas das letras traduz-se em recurso semântico cujo valor simbólico participa da construção da narrativa e da construção da obra como um todo, assegurando variadas formas de entrada do leitor ao texto, seja pelo traço que identifica a mão do escritor (que pode ser uma escolha de fonte do designer, por exemplo), seja pelo uso do espaço da folha; o fato é que a visualidade como eixo constituinte da leitura amplia os processos de produção de sentidos na leitura do livro. Necyk afirma que, "nessas aplicações, o texto impresso transmite a mensagem codificada por meio do alfabeto, mas pode também, através do efeito visual produzido, criar significados simbólicos, da mesma forma que a imagem" (NECYK, 2007, p. 90).

Não apenas a escolha tipográfica, como a própria diagramação do texto verbal, atuam no sentido de integrá-lo ao contexto visual da página, produzindo efeito sobre a narrativa e a recepção da obra. Essas relações dinâmicas entre palavra e imagem, destacadas por Belmiro (2008) como iconotexto, chamam a atenção para o que há de visual na palavra e para o que há de discursivo na imagem e, principalmente, a forma como essas duas dimensões se articulam dando origem a uma outra dimensão, que não é a soma de suas partes, mas se concretiza como uma nova estrutura plena de sentidos. 
Considerando a presença determinante da evolução técnica como um dos motivos possíveis na ordem de novas proposições, vê-se que os primeiros livros ilustrados apresentavam texto verbal e ilustração impressos em páginas separadas, sendo que as ilustrações eram relativamente escassas na escala do livro, predominantemente verbal. As inovações técnicas na indústria gráfica, especialmente a partir do século XIX, rompem com essa rigidez e a disposição espacial de texto verbal e imagem torna-se produto das escolhas editoriais em função de seu potencial narrativo, ou mesmo decorativo. Embora a primeira forma de disposição ainda subsista até os dias atuais, observa-se uma tendência a composições mais integradas entre texto e imagem nos livros infantis contemporâneos, diferenciando-os dos livros com ilustrações.

Devido a essas transformações, seja no sentido tecnológico, seja na apropriação de seus usos, verifica-se que, através da diagramação, da tipografia, dos formatos, do uso das cores e de outros recursos gráficos, além dos discursos veiculados nas capas, contracapas, orelhas ${ }^{3}$ e folhas de rosto, esses elementos articulam-se com a materialidade do livro e chamam a atenção para os mecanismos de sua produção. Questiona-se, por exemplo, a quem pertence a autoria do livro infantil. Nikolajeva e Scott (2011) analisam diferentes arranjos na produção de livros ilustrados: livros produzidos em estreita colaboração entre escritor e ilustrador, livros cujo ilustrador é escolhido pela equipe editorial e não há colaboração direta entre escritor e ilustrador, livros em que escritor e ilustrador são a mesma pessoa, entre outros.

Necyk (2007) destaca também o papel do editor e as contribuições do designer, responsáveis pela concretização do livro. Segundo a autora, embora o editor não seja um criador, ele "interfere e influencia decisivamente no processo criativo, o que determina resultados visíveis" (NECYK, 2007, p. 83). A autora comenta ainda, que "cada vez mais ilustradores têm participado como designers, o que resulta no planejamento visual do livro inteiro" (id., p. 85). Nesse caso, o aspecto global do livro revela o estilo do artista que, não apenas articula-se ao texto verbal com o objetivo de complementar o "clima" narrativo, mas induz a outras significações.

Entretanto, a complexidade do livro ilustrado é fruto não apenas de sua configuração multimodal, mas devido principalmente à sofisticação no uso das linguagens, na elaboração da narrativa, com o uso de metáforas tanto no nível verbal

\footnotetext{
3“"Extensões do papel ou outro material da capa ou da sobrecapa do livro que são dobradas para dentro da publicação a fim de dar mais apoio e rigidez. As orelhas normalmente contêm notas sobre o livro ou seu autor. [...] são ligeiramente mais estreitas que a capa a fim de serem dobradas para dentro sem fazer a capa arquear" (AMBROSE; HARRIS, 2009, p. 184).
} 
quanto visual. Nesse sentido, o livro ilustrado atrai também leitores experientes, cujo interesse está voltado para sua apreciação como objeto artístico.

Considera-se, portanto, que o livro ilustrado possui um duplo destinatário: a criança e adulto que escolhe, compra e lê o livro para a criança. Grande parte das escolhas editoriais no desenvolvimento de projetos é orientada em função das expectativas dos mediadores de leitura, em geral, pais, familiares e professores. As referências presentes no livro, tais como resenhas ou resumos da obra e biografia de autores, constantemente são pensadas considerando o adulto que escolhe o livro para as crianças.

Devido ao funcionamento do mercado editorial brasileiro de livros infantis fortemente vinculado à demanda escolar, em especial através das aquisições massivas de programas governamentais, vê-se com certa frequência o projeto gráfico do livro infantil adquirir função pedagógica que visa, antes de tudo, atrair e orientar professores na abordagem da literatura infantil em sala de aula. Assim, a produção literária para criança se mostra bastante diversificada, podendo apresentar-se mais como recurso didático auxiliar às práticas escolares de ensino da leitura e de outros conteúdos, ou como objeto artístico de alta qualidade, comprometido com a formação estética de seus leitores. Esse é um problema que a formação de um leitor literário enfrenta, uma vez que a ambiguidade entre oferecer ao público um livro literário de qualidade e ser comprado por programas governamentais para grande distribuição faz com que a obra venha com pinceladas de didatização em alguns paratextos.

Tendo em vista a configuração contemporânea dos livros infantis, este estudo interroga de que maneira sua materialidade passou a ter força e estatuto de linguagem. Buscando responder a essa questão, optamos por selecionar nosso corpus de análise entre os livros premiados pela FNLIJ na categoria Criança, no período de 1975 a 2014. Ao todo, foram analisados paratextos de 57 livros, agrupados por década (tendo por base o ano em que foram premiados), de forma a apreender permanências e mudanças em sua caracterização ao longo dos anos. As análises foram feitas com base nos pressupostos da multimodalidade, compreendendo que diferentes recursos, tais como, tipografia, o uso da cor, formatos, diagramação, bem como palavras e imagens, são passíveis de comunicar intencionalidades e sentidos, mais ou menos explícitos, participando da estrutura narrativa e modificando os modos de apreensão da obra pelo leitor. Os resultados de nossas análises serão apresentados nas seções que se seguem. 


\section{Década de 1970 (1975-1979)}

Nesse período, que corresponde aos cinco primeiros anos da premiação, as capas dos livros premiados apresentam título e ilustração em destaque. As escolhas tipográficas revelam o mesmo padrão: letras grandes, em caixa alta e tipografia simples.

\begin{tabular}{|l|l|l|l|}
\hline Título & Autor (a)/Ilustrador (a) & Editora & $\begin{array}{l}\text { Ano de } \\
\text { premiação }\end{array}$ \\
\hline O rei de quase tudo & Eliardo França & Orientação Cultural & 1975 \\
\hline Angélica & $\begin{array}{l}\text { Lygia Bojunga/Vilma } \\
\text { Pasqualini }\end{array}$ & Agir & 1976 \\
\hline A bolsa amarela & $\begin{array}{l}\text { Lygia Bojunga/ Marie } \\
\text { Louise Neri }\end{array}$ & Agir & 1977 \\
\hline Pedro & $\begin{array}{l}\text { Bartolomeu Campos } \\
\text { Queirós/Sara Ávila de } \\
\text { Oliveira }\end{array}$ & Miguilim & 1978 \\
\hline Coleção Gato e Rato & $\begin{array}{l}\text { Mary França/Eliardo } \\
\text { França }\end{array}$ & Ática & 1979 \\
\hline
\end{tabular}

Tabela 1: Livros premiados na categoria Criança entre 1975 e 1979.

As letras garrafais e as ilustrações coloridas (com exceção de Pedro, de Bartolomeu Campos de Queirós, cujas ilustrações são em preto e branco) indicam a necessidade de tornar o livro infantil um produto atrativo para o público a que se destina. As informações paratextuais na contracapa e orelhas, tais como resumos ou resenhas da obra, menção a prêmios recebidos, indicação de outros títulos de mesmo/a autor/a apresentam cunho fortemente pedagógico e se destinam mais aos mediadores adultos do que ao público infantil.

No frontispício da maioria dos livros é comum vermos as informações verbais com as letras em caixa alta na cor preta sobre fundo branco. Com exceção de Angélica, de Lygia Bojunga, cujo frontispício é decorado por uma ilustração em preto e branco emoldurando a página, a folha de rosto nos livros infantis não se diferem da produção voltada para adultos. Angélica também é o único livro do período que apresenta orelhas; estas exercem a mesma função da contracapa, com resumo da obra e biografias da autora e da ilustradora. 


\section{Década de 1980 (1980-1989)}

$\mathrm{Na}$ década de 1980 foram premiados dez livros. Observa-se maior variedade na execução dos projetos gráficos dessa produção, especialmente a partir da segunda metade da década.

\begin{tabular}{|l|l|l|l|}
\hline Título & Autor (a)/Ilustrador (a) & Editora & $\begin{array}{l}\text { Ano de } \\
\text { premiação }\end{array}$ \\
\hline Raul da ferrugem azul & $\begin{array}{l}\text { Ana Maria } \\
\text { Machado/Patrícia Gwinner }\end{array}$ & Salamandra & 1980 \\
\hline $\begin{array}{l}\text { O curumim que virou } \\
\text { gigante }\end{array}$ & $\begin{array}{l}\text { Joel Rufino dos } \\
\text { Santos/Lúcia Lacourt }\end{array}$ & Salamandra & 1981 \\
\hline $\begin{array}{l}\text { O que os olhos não } \\
\text { vêem }\end{array}$ & $\begin{array}{l}\text { Ruth Rocha/José Carlos de } \\
\text { Brito }\end{array}$ & Salamandra & 1982 \\
\hline $\begin{array}{l}\text { Uni, duni e tê } \\
\text { Os bichos que tive }\end{array}$ & Angela Lago & Compor & 1983 \\
\hline É isso ali & $\begin{array}{l}\text { José Paulo Paes/Carlos } \\
\text { Brito }\end{array}$ & Salamandra & 1984 \\
\hline $\begin{array}{l}\text { Uxa, ora fada, ora } \\
\text { bruxa }\end{array}$ & Sylvia Orthof/Tato & Nova Fronteira & 1986 \\
\hline O menino marrom & Ziraldo & Melhoramentos & 1987 \\
\hline $\begin{array}{l}\text { Uma ilha lá longe } \\
\text { minha mãe }\end{array}$ & $\begin{array}{l}\text { Cora Ronái/Rui de } \\
\text { Oliveira }\end{array}$ & Record & 1988 \\
\hline
\end{tabular}

Tabela 2: Livros premiados na categoria Criança entre 1980 e 1989.

As capas apresentam, em sua maioria, personagens da história, ora destacados sobre fundo neutro, ora em ilustrações de página inteira. As tipografias são bastante variadas e, em geral, possuem valor decorativo. Os formatos variam entre vertical e horizontal, mas com dimensões próximas entre um livro e outro.

Elementos visuais como foto do/a autor/a, ilustrações (em geral, a mesma da capa) e textos verbais acessíveis à criança se destacam na contracapa. Ilustrações e detalhes visuais aparecem com maior frequência nas folhas de rosto. Em O curumim que virou gigante vemos uma ilustração colorida ocupando grande parte da página. Já em $O$ que 
os olhos não vêem o frontispício é emoldurado pela mesma cortina que vemos na capa e os de Uni, duni e tê e $A$ mãe da mãe de minha mãe possuem detalhes decorativos. Além disso, Uni, duni e tê, Uxa, ora fada, ora bruxa, O menino marrom e Uma ilha lá longe repetem a mesma tipografia da capa, que se destacam também por sua visualidade.

As orelhas, quando aparecem, permanecem sendo usadas como espaço para veicular informações sobre o livro e os autores. Entretanto, o uso de imagens (padrões decorativos) nas guardas do livro se constitui como aspecto inovador na produção desse período.

\section{Década de 1990 (1990-1999)}

Entre os anos de 1990 e 1999 foram premiados 11 livros e uma coleção composta por 6 livros, dos quais apenas 5 foram analisados. De morte!, de Angela Lago, e $O$ problema de Clóvis, de Eva Furnari, foram premiados em 1993 como "Hors-Concours"4 juntamente com Eu e minha luneta, de Cláudio Martins.

\begin{tabular}{|l|l|l|l|}
\hline Título & Autor (a)/Ilustrador (a) & Editora & $\begin{array}{l}\text { Ano de } \\
\text { premiação }\end{array}$ \\
\hline As viagens de Raoni & $\begin{array}{l}\text { Pedro Veludo/Demóstenes } \\
\text { Vargas }\end{array}$ & Miguilim & 1990 \\
\hline Sua alteza a Divinha & Angela Lago & RHJ & 1991 \\
\hline $\begin{array}{l}\text { O menino de Olho } \\
\text { D'Aua }\end{array}$ & José Paulo Paes/Rubens Matuk & Ática & 1992 \\
\hline $\begin{array}{l}\text { Eu e minha luneta } \\
\text { (Hors-Concour) }\end{array}$ & Claudio Martins & Formato & 1993 \\
\hline $\begin{array}{l}\text { O problema de Clóvis } \\
\text { (Hors-Concour) }\end{array}$ & $\begin{array}{l}\text { Eva Furnari } \\
\text { Angela Lago }\end{array}$ & RHJ & 1993 \\
\hline Asa de papel & Marcelo Xavier & Santuário & 1993 \\
\hline $\begin{array}{l}\text { Coleção Assim é se lhe } \\
\text { parece }\end{array}$ & $\begin{array}{l}\text { Angela Carneiro, Lia Neiva, } \\
\text { Sylvia Orthof/Roger Mello, } \\
\text { Mariana Massarani, Elizabeth } \\
\text { Teixeira }\end{array}$ & Ediouro & 1995 \\
\hline
\end{tabular}

\footnotetext{
${ }^{4}$ Instituído em 1992 com objetivo de estimular novos autores, o Hors-Concours ocorre quando o mais
} votado na categoria já ganhou igual ou acima de três vezes o Prêmio FNLIJ como escritor e/ou ilustrador. 


\begin{tabular}{|l|l|l|l|}
\hline A cristaleira & $\begin{array}{l}\text { Graziela Bozano Hetzel/Roger } \\
\text { Mello }\end{array}$ & Manati & 1996 \\
\hline Menino do Rio Doce & $\begin{array}{l}\text { Ziraldo/Demóstenes Vargas } \\
\text { (desenhos) e Bordados Dumont }\end{array}$ & $\begin{array}{l}\text { Cia. das } \\
\text { Letras }\end{array}$ & 1997 \\
\hline $\begin{array}{l}\text { Minhas memórias de } \\
\text { Lobato }\end{array}$ & Luciana Sandroni/Laerte & $\begin{array}{l}\text { Cia. das } \\
\text { Letrinhas }\end{array}$ & 1998 \\
\hline Dez sacizinhos & Tatiana Belinky/Robert Weigand & Paulinas & 1999 \\
\hline
\end{tabular}

Tabela 3: Livros premiados na categoria Criança entre 1990 e 1999.

Diferentes estilos artísticos são utilizados por ilustradores/as nas imagens de capa: aquarelas, cartoon, bordados e xilogravuras antigas estão entre as técnicas/estilos empregados. A tipografia é variada, entretanto predomina a função decorativa, sem relação com o enredo. Outros elementos tais como molduras, brasões e etiquetas também são usados. A capa de $O s$ dez sacizinhos é composta por duas camadas: uma de papel grosso, todo preto, e possui corte especial ${ }^{5}$ vazado acompanhando o título e detalhes da ilustração na página abaixo; a segunda apresenta a ilustração completa e o título, entrevistos pelo corte descrito. O uso desse recurso provoca um efeito lúdico e pode ser observado também na contracapa.

Em geral, elementos visuais ao longo dos paratextos se tornam recorrentes. Fotos dos/as autores/as aparecem tanto na contracapa quanto nas orelhas; ilustrações contínuas à capa ou de mesmo estilo e detalhes decorativos são comuns, inclusive nas guardas e folhas de rosto. Por outro lado, as informações verbais aproximam-se mais do público infantil e, juntamente com as imagens, ampliam as possibilidades de acesso da criança ao livro.

\section{Década de 2000 (2000-2009)}

Já na primeira década do século XXI, as obras selecionadas se destacam pelo uso da materialidade do livro, pelo aproveitamento criativo do suporte e pelo tratamento estético dado a essas produções. Foram premiados 24 livros, entre os quais 13 são "Hors-Concours".

\footnotetext{
5“Processo de acabamento de impressão para cortar parte do suporte com uma faca de aço. Utilizado principalmente para propósitos decorativos, um corte especial pode aprimorar o impacto visual de um projeto pela criação de formas, aberturas ou bordas interessantes" (AMBROSE; HARRIS, 2009, p. 66).
} 


\begin{tabular}{|c|c|c|c|}
\hline Título & Autor (a) /Ilustrador (a) & Editora & $\begin{array}{l}\text { Ano de } \\
\text { premiação }\end{array}$ \\
\hline $\begin{array}{l}\text { Ludi na Revolta da } \\
\text { Vacina: uma odisséia } \\
\text { no Rio Antigo }\end{array}$ & $\begin{array}{l}\text { Luciana } \\
\text { Sandroni/Humberto } \\
\text { Guimarães }\end{array}$ & Salamandra & 2000 \\
\hline $\begin{array}{l}\text { ABC Doido } \\
\text { (Hors-Concour) }\end{array}$ & Angela Lago & Melhoramentos & 2000 \\
\hline $\begin{array}{l}\text { Fiz voar o meu chapéu } \\
\text { (Hors-Concour) }\end{array}$ & Ana Maria Machado & Ática & 2000 \\
\hline Chica e João & Nelson Cruz & Formato & 2001 \\
\hline $\begin{array}{l}\text { Indo não sei aonde } \\
\text { buscar não sei o quê } \\
\text { (Hors-Concour) }\end{array}$ & Angela Lago & RHJ & 2001 \\
\hline Mania de explicação & $\begin{array}{l}\text { Adriana Falcão/Mariana } \\
\text { Massarani }\end{array}$ & Salamandra & 2002 \\
\hline $\begin{array}{l}\text { Meninos do mangue } \\
\text { (Hors-Concour) }\end{array}$ & Roger Mello & Cia. das Letrinhas & 2002 \\
\hline A princesinha medrosa & Odilon Moraes & Cia. das Letrinhas & 2003 \\
\hline O dono da verdade & $\begin{array}{l}\text { Bia Hetzel/Mariana } \\
\text { Massarani }\end{array}$ & Manati & 2003 \\
\hline $\begin{array}{l}\text { De carta em carta } \\
\text { (Hors-Concour) }\end{array}$ & $\begin{array}{l}\text { Ana Maria Machado/ } \\
\text { Nelson Cruz }\end{array}$ & Salamandra & 2003 \\
\hline $\begin{array}{l}\text { Menina Nina: duas } \\
\text { razões para não chorar } \\
\text { (Hors-Concour) }\end{array}$ & Ziraldo & Melhoramentos & 2003 \\
\hline $\begin{array}{l}\text { Sete histórias para } \\
\text { sacudir o esqueleto } \\
\text { (Hors-Concour) }\end{array}$ & Angela Lago & Cia. das Letrinhas & 2003 \\
\hline O segredo da chuva & $\begin{array}{l}\text { Daniel } \\
\text { Munduruku/Marilda } \\
\text { Castanha }\end{array}$ & Ática & 2004 \\
\hline $\begin{array}{l}\text { Abrindo caminho } \\
\text { (Hors-Concour) }\end{array}$ & $\begin{array}{l}\text { Ana Maria Machado/ } \\
\text { Elizabeth Teixeira }\end{array}$ & Ática & 2004 \\
\hline $\begin{array}{l}\text { Até passarinho passa } \\
\text { (Hors-Concour) }\end{array}$ & $\begin{array}{l}\text { Bartolomeu Campos de } \\
\text { Queirós/Elizabeth Teixeira }\end{array}$ & Moderna & 2004 \\
\hline
\end{tabular}

${ }^{6} \mathrm{O}$ livro não pode ser encontrado pelas autoras e não faz parte do corpus de análise indicado. 


\begin{tabular}{|c|c|c|c|}
\hline Pedro e Lua & Odilon Moraes & Cosac Naify & 2005 \\
\hline $\begin{array}{l}\text { Murucututu: a coruja } \\
\text { grande da noite }\end{array}$ & $\begin{array}{l}\text { Marcos Bagno/Nelson } \\
\text { Cruz }\end{array}$ & Ática & 2006 \\
\hline $\begin{array}{l}\text { Cacoete } \\
\text { (Hors-Concour) }\end{array}$ & Eva Furnari & Ática & 2006 \\
\hline $\begin{array}{l}\text { João por um fio } \\
\text { (Hors-Concour) }\end{array}$ & Roger Mello & Cia. das Letrinhas & 2006 \\
\hline $\begin{array}{l}\text { Procura-se lobo } \\
\text { (Hors-Concour) }\end{array}$ & $\begin{array}{l}\text { Ana Maria Machado/ } \\
\text { Laurent Cardon }\end{array}$ & Ática & 2006 \\
\hline O menino, o cachorro & $\begin{array}{l}\text { Simone Bibian/Mariana } \\
\text { Massarani }\end{array}$ & Manati & 2007 \\
\hline $\begin{array}{l}\text { Felpo Filva } \\
\text { (Hors-Concour) }\end{array}$ & Eva Furnari & Moderna & 2007 \\
\hline O jogo de amarelinha & $\begin{array}{l}\text { Graziela Bozano } \\
\text { Hetzel/Eliza-beth Teixeira }\end{array}$ & Manati & 2008 \\
\hline $\begin{array}{l}\text { O guarda-chuva do } \\
\text { vovô }\end{array}$ & $\begin{array}{l}\text { Carolina Moreyra/Odilon } \\
\text { Moraes }\end{array}$ & DCL & 2009 \\
\hline
\end{tabular}

Tabela 4: Livros premiados na categoria Criança entre 2000 e 2009.

Em análise das capas dos livros, observamos como as ilustrações ganham destaque na composição do conjunto, efeito ressaltado também pelo uso de tipografias mais discretas e neutras. A grande maioria dos livros apresenta ilustração de página inteira, enquanto outros utilizam o fundo (ora neutro, branco ou em cor, ora com padrões decorativos) para destacar elementos da ilustração, em geral, um personagem do enredo.

Alguns livros, tais como, Felpo Filva, de Eva Furnari; Sete histórias para sacudir o esqueleto, de Angela Lago; e Procura-se lobo, de Ana Maria Machado, apresentam tipografias que se relacionam ao enredo na composição dos títulos. Contribuem dessa forma para a elaboração da totalidade estética da obra e chamam a atenção para a dimensão visual da palavra. Procura-se lobo utiliza recursos que mimetizam um pedaço de folha de jornal; o texto circulado em vermelho e as bordas irregulares do papel, indicando que o fragmento foi arrancado, remetem às ações que usualmente tomamos quando procuramos algo na seção de classificados do jornal. Dessa forma, nos livros infantis, a palavra se constitui também como imagem. 
A contracapa e a orelha do livro permanecem sendo utilizadas de maneira semelhante à década anterior. Fotos, resumos, biografias ou elementos decorativos aparecem nestes espaços. Há também o uso de cores chapadas, sem qualquer outra informação, visual ou verbal, tanto em contracapas quanto em orelhas. Já as guardas do livro passam a ser pensadas, de maneira mais extensiva, como espaço de significações que ampliam o valor estético da obra.

\section{Década de 2010 (2010-2014)}

Nesse período, destacam-se a composição do livro como um todo e a forte influência de concepções do design presentes nas obras.

\begin{tabular}{|l|l|l|l|}
\hline Título & Autor (a)/Ilustrador (a) & Editora & $\begin{array}{l}\text { Ano de } \\
\text { premiação }\end{array}$ \\
\hline O lobo & $\begin{array}{l}\text { Graziela Bozano } \\
\text { Hetzel/Elizabeth Teixeira }\end{array}$ & Manati & 2010 \\
\hline $\begin{array}{l}\text { Palhaço, macaco, } \\
\text { passarinho }\end{array}$ & Eucanaã Ferraz/Jaguar & Cia. das Letrinhas & 2011 \\
\hline O alvo & $\begin{array}{l}\text { Ilan Brenman/Renato } \\
\text { Moriconi }\end{array}$ & Ática & 2012 \\
\hline Visita à baleia & $\begin{array}{l}\text { Paulo Venturelli/Nelson } \\
\text { Cruz }\end{array}$ & Positivo & 2013 \\
\hline $\begin{array}{l}\text { Sete patinhos na lagoa } \\
\text { Caio Riter/Laurent Cardon }\end{array}$ & Biruta & 2014 \\
\hline $\begin{array}{l}\text { Bichos do lixo } \\
\text { pequeno amor } \\
\text { (Hors-Concour) }\end{array}$ & Ferreira Gullar & Casa da Palavra & 2014 \\
\hline
\end{tabular}

Tabela 5: Livros premiados na categoria Criança entre 2010 e 2014.

Na capa dos livros, as propostas de diagramação se destacam ao colocar em diálogo os diferentes elementos que a compõem. Em Palhaço, macaco, passarinho a ilustração interage com o título, enquanto em $O$ alvo, o título, pintado sobre uma cerca de madeira, faz parte da ilustração. Elementos como sobrecapa e cortes especiais adquirem dimensão narrativa. $\mathrm{O}$ uso da sobrecapa ${ }^{7}$ em $O$ lobo materializa o livro de

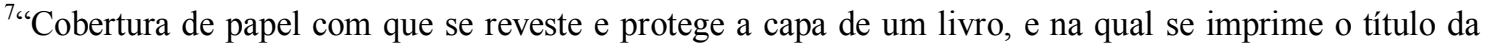
obra, nome do autor, etc.", in Dicionário Priberam da Língua Portuguesa. Disponível em: http://www.priberam.pt/dlpo/sobrecapa
} 
histórias que Lilia e seu pai leem todas as noites. Um livro dentro de um livro. A metalinguagem constitui-se um dos aspectos da literatura pós-moderna que vem sendo amplamente utilizado na literatura infantil contemporânea.

$\mathrm{Na}$ capa de $O$ alvo, há um grande círculo vazado pelo qual entrevemos um homem com uma suposta maçã sobre a cabeça. A fruta é representada por outro círculo vazado, porém menor, que percorre todo o livro, com exceção da última página do miolo e da contracapa. A cada página, o círculo é utilizado como parte da ilustração, seja na composição do cenário ou mesmo dos personagens. Instaura, dessa forma, um efeito lúdico e chama a atenção para a materialidade do livro e os processos de sua produção.

Os demais paratextos revestem-se de caráter fortemente visual, seja através do uso das cores, de elementos gráficos ou da presença de ilustrações em guardas, folhas de rosto e orelhas. Percebe-se também a presença de cores, tipografias e detalhes mais discretos ou neutros que nos remetem a uma estética minimalista e, diferentemente de décadas anteriores, evidenciam uma escolha cuidadosamente pensada. Além disso, os discursos verbais voltam-se marcadamente para o público infantil por meio de uma linguagem leve, bem humorada e acessível.

\section{CONSIDERAÇÕES FINAIS}

A partir de nossas análises, observa-se que algumas propostas na elaboração do livro ilustrado se tornam recorrentes, como, por exemplo, a presença marcante de ilustrações nas capas dos livros analisados e a articulação, em diferentes níveis, entre elementos verbais e visuais; por outro lado, outras apresentam caráter bastante original, a saber, a apresentação dos autores da obra com retratos e textos em linguagem simples e bem humorada ao final da narrativa, no nível do leitor mirim; a presença acentuada de elementos visuais que instauram, através de cores, linhas, formas e texturas novos espaços de significação, começando pela orelha, estendendo-se pelas páginas de guarda, frontispício etc., o aproveitamento do suporte através de cortes especiais ou formatos diferenciados.

Se, na década de 1970, o livro infantil brasileiro passou por grande efervescência artística propiciando o surgimento de novos autores e também ilustradores e elevando a qualidade estética do livro infantil, observa-se, nas obras premiadas nesse período, a atenção à qualidade artística e literária dos livros, ao mesmo tempo em que os paratextos evidenciam a presença do adulto como o primeiro a selecionar as obras, 
cabendo a eles, portanto, a primazia da interlocução. Nos anos subsequentes, a partir da década de 1980 até os dias atuais, observamos o uso acentuado de elementos visuais onde, antes, predominava o texto verbal. Resenhas e biografias passam a ser acompanhadas de fotos e pequenas ilustrações. A visualidade, utilizada tanto como elemento decorativo quanto como recurso narrativo, começa a se instituir como principal aspecto que caracteriza essa produção. A materialidade do livro ganha estatuto de linguagem e entra no jogo de produção sentidos ao apresentar formatos, recortes, texturas diferenciadas que aproximam o livro do universo da criança e lhe possibilita múltiplas formas de entrada e de significação.

O uso sofisticado de diferentes linguagens e recursos semióticos evidenciam a presença da multimodalidade na composição dos paratextos do livro infantil e o potencial da literatura na formação estética de seus leitores, liberando a literatura infantil de associações didáticas e pedagógicas. Na produção contemporânea de literatura infantil, a criança passa então a ser vista como leitora crítica, participante ativa nos processos de escolha, leitura e produção de sentidos, seja por meio dos diferentes recursos semióticos que lhes propiciam formas diferenciadas de leitura e apreensão dos conteúdos de um livro, ou ainda por meio de um discurso leve e conciso nas resenhas, resumos e biografias que o introduzem.

O que se vê, portanto, é a potencialização máxima desse material, atraindo leitores de diferentes faixas etárias, sendo apropriado para diferentes realizações artísticas, transformando-se em livro de artista e mostrando que os dias atuais permitem abrir diálogo com diferentes campos e linguagens. Tanto a visualidade desses livros, quanto sua proposta narrativa, indicam a necessidade de repensar o conceito de literatura, integrando os variados modos de composição artística, de estratégias de organização discursiva do enredo, bem como sua materialidade.

O livro ilustrado é tão somente um livro infantil? Observa-se que as temáticas as mais diversas e as obras que se apropriam de tantas materialidades vem mostrando que os bebês também devem estar em contato com esses materiais. Essa clareza talvez seja o caminho mais adequado de se compreender que leitores somos e que leitores desejamos formar. 


\section{REFERÊNCIAS}

AMBROSE, G.; HARRIS, P. Dicionário visual de Design Gráfico. Porto Alegre: Bookman, 2009.

BELMIRO, C. A. Um estudo sobre relações entre imagem e textos verbais em cartilhas de alfabetização e livros de literatura infantil. 2008. $283 \mathrm{f}$. Tese (Doutorado em Educação). Faculdade de Educação, Universidade Federal Fluminense, Niterói, 2008.

A multimodalidade na literatura infantil e a formação de professores leitores. RBLA, Belo Horizonte, v. 10, n. 2, p. 403-420, 2010.

. Entre modos de ver e modos de ler, o dizer. Educação em Revista, Belo Horizonte, v. 28, n. 4, p. 105-131, 2012.

. Provocação e imaginação: diálogos entre descrição e narração na literatura infantil. Idioma, Rio de Janeiro, n. 27, p. 06-18, 2015.

CHRISTIN, Anne- Marie. A imagem enformada ela escrita. IN: ARBEX, Márcia. (Org.) Poéticas do visível: ensaios sobre a escrita e a imagem. Belo Horizonte: Programa de Pós-Graduação em Letras: Estudos literários, Faculdade de Letras, UFMG, 2006.

GENETTE, G. Paratextos Editoriais. São Paulo: Ateliê Editorial, 2009.

KRESS, G.; BEZEMER, J. Escribirenun mundo de representación multimodal. In: KALMAN, J.; STREET, B. (Org). Lectura, Escritura y Matemáticas como prácticas sociales: Diálogos desde los Estudios Latinoamericanos sobre Cultura Escrita. México: Siglo XXI, CREFAL (Centro de Cooperación Regional para la Educación de Adultos en América Latina y el Caribe), 2000.

LEITE, L. F. S. Modos de ler e ser: a poética dos livros ilustrados. 2013. 219 f. Tese (Doutorado em Letras). Instituto de Letras, Universidade do Estado do Rio de Janeiro. Rio de Janeiro, 2013.

LINDEN, S. V der. Para ler o livro ilustrado. São Paulo: Cosac Naify, 2011.

NECYK, B. J. Texto e imagem: um olhar sobre o livro infantil contemporâneo. 2007. 167 f. Dissertação (Mestrado em Design). Centro de Teologia e Ciências Humanas, Pontifícia Universidade Católica do Rio de Janeiro. Rio de Janeiro, 2007.

NIKOLAJEVA, M.; SCOTT, C. Livro ilustrado: palavras e imagens. Trad. Cid Knipel. São Paulo: Cosac Naify, 2011.

OLIVEIRA, I. (Org.). O que é qualidade em ilustração no livro infantil e juvenil: com a palavra o ilustrador. São Paulo, DCL: 2008. 
OLIVEIRA, R. Pelos Jardins Boboli: reflexões sobre a arte de ilustrar livros para crianças e jovens. Rio de Janeiro: Nova Fronteira, 2008a.

POWERS, A. Era uma vez uma capa: história ilustrada da literatura infantil. São Paulo: Cosac Naify, 2012.

\begin{abstract}
AS AUTORAS
Tatyane Andrade Almeida é mestranda em Educação pelo Programa de PósGraduação: Conhecimento e Inclusão Social em Educação da Faculdade de Educação da UFMG. É professora de Educação Infantil pela rede municipal de Belo Horizonte. Participa do grupo de pesquisa Leitura e Escrita na Primeira Infância - Lepi - e do grupo Literartes, ambos da Faculdade de Educação/UFMG. Atua principalmente nos seguintes temas: literatura infantil, livro ilustrado, linguagem visual, leitura e escrita e crianças.
\end{abstract}

E-mail: tatyaneandrade2008@gmail.com

Celia Abicalil Belmiro é professora do Programa de Pós-Graduação em Educação da UFMG, pesquisadora do Centro de Alfabetização, Leitura e Escrita (CEALE/UFMG). Pesquisa sobre literatura infantil, livros ilustrados, literatura infantil e mídia e contemporaneidade, formação literária do professor. É consultora de programas governamentais para seleção de livros a serem distribuídos às bibliotecas públicas escolares brasileiras. Editora adjunta de Educação em Revista (FaE/UFMG) e editora dos livros Livros e Telas e Onde está a literatura: seus espaços, seus leitores, seus textos, suas leituras.

E-mail: celiaabicalil@gmail.com 